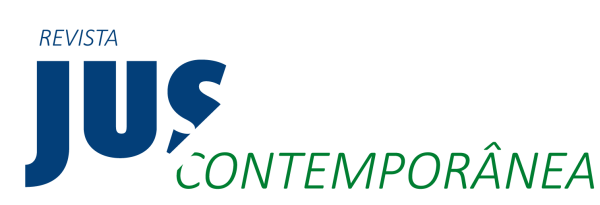

ARTIGO

https://doi.org/10.30749/2674-9734.v2n0a484

\title{
DIREITO À CIDADE E À MORADIA: O VÁCUO ENTRE A LEI E A REALIDADE
}

\section{THE RIGHT TO THE CITY AND HOUSING: THE GAP BETWEEN THE LAW AND REALITY}

\author{
Mário Luiz da Silva ${ }^{1}$ \\ Patrícia Maria Dusek ${ }^{2}$ \\ Maria Geralda de Miranda ${ }^{3}$
}

Resumo: Evocando as ideias do filósofo francês Henri Lefebvre acerca do conceito de "direito à cidade", que engloba uma série de outros direitos que dariam aos cidadãos um espaço de vida mais adequado à dignidade humana, este artigo pretende abordar a questão da moradia, hoje elevada à condição de direito fundamental. Pretende também falar dos efeitos da migração interna nos grandes centros urbanos, dos conceitos e alguns princípios norteadores das políticas públicas, com foco no problema "moradia adequada", e de como tais noções teóricas podem ajudar a jogar luz sobre os resultados de algumas práticas já implementadas na área, notadamente quanto ao Programa Minha Casa, Minha Vida, questionando se isso tem ajudado a tornar efetivo tudo o que vem sendo consagrado pela legislação brasileira relacionada aos problemas habitacionais, urbanísticos e sociais.

Palavras-chave: Direitos. Cidade. Políticas Públicas. Moradia. Legislação. Cidadania.

Abstract: Evoking the ideas of the French philosopher Henri Lefebvre about the concept of "right to the city", which embraces many other rights that are responsible for giving the citizens a more adequate space to human dignity, this article intends to approach the housing issue, nowadays raised to the status of fundamental right. It also intends to discuss the effects of internal migration in major urban centers and the concepts and some principles guiding of public policies focused on the issue "adequate housing", and how this theoretical notions can help to understand the results of some practices already implemented in this area, notably about the

\footnotetext{
${ }^{1}$ Bacharel em Direito pela UGF; pós-graduado em Direito Penal e Direito Processual Penal pela UNESA. Mestrando pelo Programa de Pós-Graduação em Desenvolvimento Local do Centro Universitário Augusto Motta, UNISUAM. E-mail: skilerd7@gmail.com. ORCID: https://orcid.org/0000-0001-6698-2690

2 Pós-doutora em Justiça Constitucional pela Università di Pisa. Coordenadora e Pesquisadora do Programa de Pós-graduação em Desenvolvimento Local do Centro Universitário Augusto Motta, UNISUAM, Rio de Janeiro, RJ. E-mail: patricia.dusek@unisuam.edu.br. ORCID: https://orcid.org/0000-0003-3911-6943

${ }^{3}$ Pós-doutora em Políticas Públicas e Formação Humana pela Universidade do Estado do Rio de Janeiro (UERJ). Pesquisadora do Programa de Pós-graduação em Desenvolvimento Local do Centro Universitário Augusto Motta, UNISUAM, Rio de Janeiro, RJ. E-mail: mgeraldamiranda@gmail.com. ORCID: https://orcid.org/0000-0002-2461-7414
} 
DIREITO À CIDADE EÀ MORADIA: O VÁCUO ENTRE A LEI E A REALIDADE
Mário Luiz da Silva Patrícia Maria Dusek Maria Geralda de Miranda

Program "Minha Casa, Minha Vida", wondering if this is helping to make effective everything that's being established by Brazilian legislation concerning housing, social and urban development problems.

Keywords: Rights. City. Public Policy. Housing. Legislation. Citizenship.

Recebido em: 05/11/2020 Aceito para publicação em: 22/09/2021 


\section{INTRODUÇÃO}

Ao contrário de significar um conjunto de quimeras filosóficas, apartadas da realidade, o ideário que sustenta os conceitos sobre o direito à cidade pode ser considerado como um elenco de propostas concretas e voltadas à conquista de uma vida melhor para as pessoas, a partir da construção de um ambiente mais humanizado, onde sejam priorizados os anseios e necessidades reais de seus habitantes.

Não sendo possível falar em humanização sem tratar do oferecimento de moradias dignas aos cidadãos, surge a importância de que seja analisada a transformação dos princípios informadores do direito à cidade em comandos normativos, bem como da eficácia das ações e políticas públicas destinadas a garantir esse direito essencial: morar com dignidade.

Passando por uma visão sobre déficit habitacional, êxodo rural e impacto da migração na realidade das cidades, além da abordagem de conceitos e alguns princípios informadores das políticas públicas, busca-se aqui definir se os avanços legislativos dirigidos à matéria estão conseguindo dar efetividade às garantias assinaladas nos textos das leis, ou seja, verificar se a consagração legal do direito à cidade e o reconhecimento da habitação como direito fundamental estão transformando os nossos territórios, sejam na cidade ou no campo, em lugares para se viver melhor.

\section{O DIREITO À CIDADE}

A noção de Direito à Cidade tem por base uma série de postulados filosóficos do francês Henri Lefebvre que, em sua obra, Le Droit à La Ville ("O Direito à Cidade"), de 1967, defendia, em linhas gerais, a conquista de uma série de condições que direcionassem aos cidadãos possibilidades de viver em condições dignas e saudáveis. Leciona Lefebvre, citado por Harvey (2014, p. 11) que

(...) Esse direito (...) era, ao mesmo tempo, uma queixa e uma exigência. A queixa era uma resposta à dor existencial de uma crise devastadora da vida cotidiana na cidade. A exigência era, na verdade, uma ordem para encarar 
a crise nos olhos e criar uma vida urbana alternativa que fosse menos alienada, mais significativa e divertida (...) (LEFEBVRE, 1967 apud HARVEY, 2014, p. 11).

Mais adiante, David Harvey afirma que "(...) as ideias de Lefebvre surgiram basicamente das ruas e bairros de cidades doentes. Desse modo (...) os movimentos pelo direito à cidade encontram-se em plena atividade em dezenas de cidades de todo o mundo" (HARVEY, 2014, p. 15) e conclui, definindo o direito à cidade como "(...) muito mais do que um direito de acesso individual ou grupal aos recursos que a cidade incorpora: é um direito de mudar a reinventar a cidade mais de acordo com nossos mais profundos desejos (...)" (HARVEY, 2014, p. 28).

Em seu trabalho intitulado "Direito à Cidade, Cidades Para Todos e Estrutura Sociocultural Urbana", Roberta Amanajás e Letícia Klug (2018, p. 29) pontificam que

(...) O direito à cidade é um direito difuso e coletivo, de natureza indivisível, de que são titulares todos os habitantes da cidade, das gerações presentes e futuras. Direito de habitar, usar e participar da produção de cidades justas, inclusivas, democráticas e sustentáveis. A interpretação do direito à cidade deve ocorrer à luz da garantia e da promoção dos direitos humanos, compreendendo os direitos civis, políticos, sociais, econômicos e culturais reconhecidos internacionalmente a todos.

Observa-se nesta definição o destaque à questão da moradia, do direito à habitação, por nós considerado como um fundamental indicador da existência (ou não) do oferecimento efetivo de cidadania e justiça social às populações.

Dessa forma, é permitido chegar à conclusão de que o direito à cidade não se trata de uma abstração, mas sim de um conjunto de ideias concretas, que servem de base para a compreensão da questão das desigualdades sociais, através do que se buscará a construção de ferramentas garantidoras de uma forma de vida com mais humanidade.

\section{A CONSTITUIÇÃO BRASILEIRA E O DIREITO À CIDADE}

Corroborando para a afirmativa de Harvey quanto à plena atividade dos movimentos pelo direito à cidade em vários lugares pelo mundo, há em nosso país, 
que a Constituição da República vigente representou um passo significativo para o reconhecimento do direito à cidade. Em trabalho elaborado pelo IPEA, em 2016, e organizado por Marco Aurélio Costa, denominado "O Estatuto da Cidade e a Habitat III: um Balanço de Quinze Anos da Política Urbana no Brasil a Nova Agenda Urbana", os colaboradores Barbara O. Marguti e Ernesto P. Galindo, em artigo construído juntamente com o organizador, lembram que

(...) a sistematização das concepções de uma nova cidade idealizada se deu através da Proposta de Emenda Popular pela reforma Urbana, de 1987, que decorreu dos movimentos populares, organizações não governamentais, grupos religiosos, universidade, organizações políticas e associações profissionais, reunidos em torno da plataforma pela reforma urbana (Fórum Nacional da Reforma Urbana). (COSTA; MARGUTI; GALINDO, 2016, p. 15).

Todos os direitos mencionados nos artigos $1^{\circ}$ e $2^{\circ}$ da citada proposta foram devidamente consagrados em nossa Carta Magna (artigos 182 e 183) e posteriormente ratificados com sua regulamentação pelo Estatuto das Cidades (artigo 20 e incisos), a seguir (BRASIL, 2009).

A leitura de Carta Magna do Brasil, mais especificamente do Título VII e seu Capítulo II, que tratam da Ordem Econômica e Financeira e da Política Urbana, permite identificar vários assuntos ligados ao tema, como o Artigo 182, que versa sobre a política de desenvolvimento urbano, outorgada aos municípios, firmando como meta principal o pleno desenvolvimento das funções sociais da cidade e a garantia do bem-estar dos habitantes. Trata, ainda, dos planos diretores e da função social da propriedade ( $\S \S 1^{\circ}$ e $2^{\circ}$ ). Também os Artigos 183 e 225 são vinculados à questão, visto que disciplinam, respectivamente o usucapião urbano e o direito geral ao meio ambiente equilibrado (BRASIL, 1988).

Na mesma esteira, surge em 2001 o Estatuto das Cidades (Lei no 10.257), que se trata de um conjunto de normas de regulação geral, posto que a cada município foi outorgada a atribuição de efetivar as normativas de acordo com suas realidades específicas. O Estatuto veio regulamentando o texto constitucional e trazendo uma gama de temas preconizados no ideário de Lefebvre, podendo ser destacados, em seu Artigo 20, a sustentabilidade (inc. I), aqui afirmando que as cidades sustentáveis 
incluem direitos diversos, como direito à terra urbana, à moradia, ao saneamento ambiental, à infraestrutura urbana, transporte, serviços públicos, trabalho e lazer, com foco nas gerações presentes e, também, nas futuras (BRASIL, 2009).

Conveniente extrair deste texto legal as preocupações com o acesso à terra urbana e com a moradia, visto que a falta de políticas públicas adequadas e efetivamente voltadas aos interesses primordiais das populações menos favorecidas tem gerado efeitos deletérios a todos os cidadãos, sejam aqueles que não têm onde morar (ou moram em condições sub-humanas), sejam aqueles que, ainda que bem instalados, terão de suportar as consequências da busca pela moradia pelos necessitados, francamente tendente a causar danos urbanísticos e/ou ambientais (desmatamento, construções irregulares, esgotamento sanitário precário etc.). 0 dispositivo também menciona a gestão democrática pela participação popular (inc. II), distorções do crescimento urbano e efeitos negativos sobre o meio ambiente (inc. IV), e a oferta de equipamentos, transporte e serviços adequados aos interesses e necessidades da população (inc. V).

Importante, assim, pontuar a observação de Costa, ao afirmar:

O Estatuto das Cidades é, em si mesmo, a consolidação do processo que busca conferir o direito da cidade à população brasileira, não se restringindo à sua porção urbana, mas cobrindo, ainda que em distintas perspectivas, a população de cada um dos municípios brasileiros. É, como dito anteriormente, o resultado das lutas dos movimentos sociais urbanos organizados em torno da bandeira pela reforma urbana, sobretudo daqueles que se insurgem-na defesa pela moradia adequada, esta entendida para além da casa em si, mas também como um direito humano e fundamental reconhecido desde 1948 (a partir da Declaração Universal dos Direitos Humanos) -, trazendo em seu bojo uma série de outros direitos que se interconectam ao direito à cidade, como a segurança da posse, a disponibilidade de serviços de infraestrutura e equipamentos públicos, a habitabilidade e a localização adequada (COSTA, 2016, p. 15).

É lídimo destacar a visão de que, embora a nossa Carta Magna mencione de forma expressa normas de "ordenamento urbano" e sendo o Estatuto das Cidades o instrumento para regulamentação de tais normas, a preocupação não se prende apenas aos espaços urbanos, entendidos como territórios das cidades e contrapondo-se aos territórios rurais. Direito à cidade e, por conseguinte, à moradia, 
se refere à dignidade "de vida" e "devida" a todo cidadão, a cada "Zé" presente em qualquer parte do nosso chamado "país continental", respeitadas as peculiaridades de cada local. A desatenção a um espaço determinado sempre carregará a tendência de criar consequências desastrosas para todos os demais espaços e, portanto, a busca de soluções deve ser estabelecida com base na integração e interação de todos os atores, direta ou indiretamente afetados pelo problema.

\section{SOCIEDADE CIVIL, DIREITO À CIDADE E DIREITO À HABITAÇÃO}

Como já se vê, o Estatuto das Cidades foi o instrumento pelo qual o legislador infraconstitucional tratou de regulamentar e dar efetividade aos ditames da Constituição, no que se refere às políticas urbanas. O diploma legal, ao disciplinar os planos diretores, conferiu à sociedade civil um papel de destaque na elaboração e controle das políticas públicas, conforme se observa no Artigo 40 e seu $\S 40$, que possuem o seguinte teor:

Art. 40. O plano diretor, aprovado por lei municipal, é o instrumento básico da política de desenvolvimento e expansão urbana.

$\S 4^{\circ}$. No processo de elaboração do plano diretor e na fiscalização de sua implementação, os Poderes Legislativo e Executivo municipais garantirão:

I - a promoção de audiências públicas e debates com a participação da população e de associações representativas dos vários segmentos da comunidade;

II - a publicidade quantos aos documentos e informações produzidos;

III - 0 acesso de qualquer interessado aos documentos e informações produzidos (BRASIL, 2009).

Ainda sobre este tema, Dowbor (2016) menciona em sua obra "O Que é o Poder Local" a experiência da cidade de Grenoble, na França, onde os moradores chamaram para si a organização do espaço de habitação, otimizando suas condições de vida, esclarecendo:

(...) O problema central, portanto, é o da recuperação do controle do cidadão, no seu bairro, na sua comunidade, sobre as formas de seu desenvolvimento, sobre a criação das coisas concretas que levam a que a nossa vida seja agradável ou não (...). (DOWBOR, 2016, p. 9, 11). 
A participação da sociedade civil nas discussões e na sedimentação dos princípios informadores do direito à cidade, e de todas as garantias e prerrogativas vinculadas ao conceito, se cristalizam nos fóruns sociais realizados em diversas partes do mundo, onde são discutidos os mais diversos assuntos correlatos à matéria, como a exploração da terra, o acesso à água limpa e a segurança alimentar. A este respeito, merece atenção O Fórum Social Mundial Policêntrico, citado por Costa, composto por eventos realizados em Quito, Equador (Fórum Social das Américas, em 2004), Barcelona, Espanha (Fórum Mundial Urbano, em 2004) e Porto Alegre, Brasil (V Fórum Social Mundial), de onde se extraiu uma nova versão da Carta Mundial Pelo Direito à Cidade (COSTA, 2016, p.13).

Sendo considerada um dos principais documentos de referência ao direito à cidade produzidos em fóruns sociais - Amanajás e Klug mencionam, ainda, a Carta-Agenda Pelos Direitos Humanos nas Cidades e a Carta da Cidade do México Pelo Direito à Cidade, ambas de 2009, além da Carta do Rio de Janeiro Sobre Direito à Cidade, de 2010 (2018, p. 30) -, a Carta Mundial pelo Direito à Cidade, em seu preâmbulo, define como missão estabelecer

\begin{abstract}
(...) compromissos e medidas que devem ser assumidos por toda a sociedade civil, pelos governos locais e nacionais e pelos organismos internacionais para que todas as pessoas vivam com dignidade em nossas cidades" (p.1), e se apresenta como "Um instrumento dirigido a contribuir com as lutas urbanas e com o processo de reconhecimento, no sistema internacional de Direitos Humanos, do direito à cidade...". Mais adiante afirma que "O direito à cidade democrática, justa, equitativa e sustentável pressupõe o exercício de todos os direitos econômicos, sociais, culturais, civis e políticos previstos em pactos e convênios internacionais de Direitos Humanos, por todos os habitantes, tais como... o direito a uma habitação adequada, o direito à saúde, o direito à água, o direito à educação (...) (CARTA MUNDIAL PELO DIREITO À CIDADE, 2005, p. 2-3).
\end{abstract}

Observa-se nitidamente que a questão da moradia é tida como prioritária no tocante à consecução ou oferecimento de condições adequadas de vida à população. Como já mencionado, o tema é tratado especificamente na Declaração Universal dos Direitos Humanos, que em seu Artigo XXV determina que "Todo ser humano tem direito a um padrão de vida capaz de assegurar-lhe, e à sua família, saúde e bem-estar, inclusive alimentação, vestuário, habitação, cuidados médicos e 
serviços sociais indispensáveis..." (ONU, 1948). Assim, foi o direito à habitação elevado à categoria de direito fundamental, essencial à vida humana digna, e o nosso legislador constitucional não fechou os olhos à relevância do tema, estando devidamente inserido no Artigo $6^{\circ}$ de nossa Carta Magna, com redação dada pela Emenda Constitucional no 90, de 2015, e que assim pontifica:

Art.60- São direitos sociais a educação, a saúde, a alimentação, o trabalho, a moradia, o transporte, o lazer, a segurança, a previdência social, a proteção à maternidade e à infância, à assistência aos desamparados, na forma desta Constituição (BRASIL, 1988).

Tratando-se de um direito e garantia fundamental, o direito à habitação é considerando uma cláusula constitucional pétrea, ou seja, não suscetível de alteração negativa através de processo de emenda, na forma do Artigo 60, § 40 da Constituição da República: "Art. 60- A Constituição poderá ser emendada mediante proposta: (...) §40: Não será objeto de deliberação a proposta tendente a abolir: (...) IV- os direitos e garantias individuais."

Ainda tratando da Carta Mundial pelo Direito à Cidade, esta reserva um capítulo especial para tratar da questão habitacional, versando o Artigo XIV especificamente sobre o direito à moradia. Importante destacar os seguintes compromissos, assumidos pelas cidades signatárias:

(...) medidas para garantir a todos(as) os(as) cidadãos(ãs) que os custos da moradia serão proporcionais à renda de cada cidadão... (item 1); "...facilitar uma oferta adequada de habitação e equipamentos de bairro para todos os(as) cidadãos(ãs) e de garantir às famílias em situação de pobreza planos de financiamento... (item 2). Fala ainda o item 5 que "Todos os cidadãos, em forma individual, casais ou grupos familiares sem lar têm o direito de exigir a provisão imediata pelas autoridades públicas das cidades de habitação suficiente, independente e adequada (...) (CARTA MUNDIAL PELO DIREITO À CIDADE, 2005, p. 11-31).

A sociedade civil e os legisladores, como se vê em muitos casos, já despertaram para a essencialidade do tema "habitação", dada sua importância para as populações em sua busca por direitos minimamente humanos. Todavia, é possível 
vislumbrar ações efetivas das autoridades públicas no sentido de transformar esse direito em realidade?

\section{CONCEITOS E PRINCÍPIOS INFORMADORES DAS POLÍTICAS PÚBLICAS APLICADOS AO PROBLEMA "MORADIA"}

O entendimento acerca de um determinado tema pode ser, muitas vezes, facilitado se buscarmos a compreensão sobre seus conceitos e princípios informadores. No tocante às políticas públicas e ao papel do Estado em suas formulações (num enfoque estatista), isso não seria diferente. Em "Análise de Políticas Públicas", Leonardo Secchi informa que a ciência da política pública tem origem no ano de 1951, com a publicação do livro "The Policy Sciences", por David Lerner e Harold D. Lasswell, possuindo lastro em três características originárias: normatividade (por sua lógica vinculação com regras e preceitos imperativos), multidisciplinaridade (por envolver questões de interesse de áreas de conhecimento diversas, como sociologia, direito, economia etc.) e resolução de problemas públicos. Vale observar que o autor aponta para uma mitigação das duas primeiras características nos tempos atuais, uma vez que a normatividade "perdeu espaço para a pesquisa política (...) com viés teórico", enquanto a multidisciplinaridade "(...) também cedeu espaço com a consolidação de um vocabulário próprio (...) e referenciais teórico-metodológicos próprios do campo disciplinar da política pública" (2021, p. 7-9).

Publicado pelo SEBRAE-MG, em 2008, o trabalho "Políticas Públicas Conceitos e Práticas", coordenado por Ricardo Wahrendorff Caldas (2008, p. 5), aponta que

A função que o Estado desempenha em nossa sociedade sofreu inúmeras transformações ao passar do tempo. Nos séculos XVIII e XIX seu principal objetivo era a segurança pública e a defesa externa em caso de ataque inimigo... Entretanto, com o aprofundamento e expansão da democracia as responsabilidades do Estado se diversificaram. Atualmente é comum se afirmar que a função do Estado é promover o bem-estar da sociedade.... Para atingir resultados em diversas áreas e promover o bem-estar da sociedade, os governos se utilizam das políticas públicas, que podem ser definidas como um 
conjunto de ações e decisões de governo, voltadas para a solução (ou não) de problemas da sociedade.

O professor Álvaro Chrispino defende que "o conceito de política pública é resultado de inúmeras variáveis (...) e que seu significado será tão distinto quanto os valores, ideologias, contextos, ética etc. de seu formulador" (2016, p. 17). E preleciona:

(...) se entendermos a política pública como um instrumento político e de governo que pretende atender às necessidades da sociedade, deveremos fechar um interessante e moderno "círculo virtuoso de poder social": a sociedade democrática... escolhe os dirigentes dos poderes Legislativo e Executivo como seus representantes, e esses produzem políticas públicas que retornam ao cidadão na proteção e execução de seus direitos. (CHRISPINO, 2016, p. 30)

Podemos perceber que, neste campo, alguns fatores são indissociáveis: problema, sociedade e bem-estar. Vale dizer, portanto, que uma política pública efetiva precisará estar voltada à construção do bem-estar através da busca de soluções para um problema que precise ser afastado da vida do cidadão, ou para uma necessidade coletiva que precise ser satisfeita.

Em abordagem precisa, Leonardo Secchi estabelece que o problema público "trata do fim ou da intenção de resolução", enquanto a política pública trata "do meio ou mecanismo para levar a cabo tal intenção". E esclarece:

O problema público é um conceito intersubjetivo, ou seja, ele só existe se incomoda uma quantidade ou qualidade considerável de atores... Política pública é um conceito abstrato que se materializa com instrumentos concretos como, por exemplo, leis, programas, campanhas, obras, prestação de serviço, subsídios, impostos e taxas, decisões judiciais, entre muitos outros. 0 problema público está para a doença, assim como a política pública está para o tratamento... a doença (problema público) precisa ser diagnosticada, para então ser dada uma prescrição médica de tratamento (política pública) (...). (SECCHI, 2021, p. 5)

Conveniente cotejar a questão da moradia e o caráter de intersubjetividade do problema público identificado por Secchi. Numa avaliação açodada, talvez chegássemos à conclusão de que a habitação não seria um "problema público" se 
observássemos tão-somente as dificuldades de determinada pessoa ou grupo familiar para conseguir moradia adequada. Todavia, se faz necessária a compreensão de que uma crise habitacional não atinge apenas quem se encontre diretamente ao desamparo de medidas saneadoras. Consequências deletérias óbvias, como ocupação irregular, insuficiência de saneamento básico e de redes de transporte e saúde, afrontas ambientais e à segurança coletiva, entre outros, afirmam que a questão habitacional atinge a sociedade como um todo, sendo, portanto, um típico caso de problema público a exigir respostas urgentes e efetivas.

\section{6 ÊXODO RURAL, SOBRECARGA NOS GRANDES CENTROS E CRISE HABITACIONAL}

Inegavelmente, a moradia é um direito essencial à vida humana. Tal importância se dará tanto no campo quanto nos espaços urbanos, onde a questão ganha contornos dramáticos decorrentes do recebimento de grande número de homens, mulheres e crianças que são expulsos de seus locais de origem por fatores diversos, notadamente em razão à gritante diferença na qualidade de vida entre o campo e as cidades. Daí o êxodo rural ser definido como um "fenômeno social que resulta na migração da população rural para os centros urbanos, com o objetivo de garantir melhores condições de vida" (ÊXODO RURAL, 2020).

Tratando dos diagnósticos do problema público, Secchi afirma que "(...) um problema público que se torna evidente na atualidade é geralmente reflexo do passado" (2021, p. 39). O Censo Demográfico IBGE de 2010 nos trouxe dados de fundamental importância para a reflexão acerca dos impactos do êxodo rural na realidade dos centros urbanos e de todas as consequências deletérias eventualmente decorrentes do fenômeno. A pesquisa mostra que, num período de 40 anos, compreendido entre os anos de 1960 e 2010, a população rural caiu de cerca de 38.900 pessoas para algo em torno de 29.800 , representando uma diminuição de cerca de 24 pontos percentuais. Ao mesmo tempo, a população urbana saltou de cerca de 32.000 pessoas para 160.900 , ou seja, um aumento aproximado de $500 \%$. 
Os números de 1960 indicavam que o ambiente rural representava cerca de $55 \%$ da população brasileira, ao passo que a população urbana girava em torno de $44 \%$. Hoje, se têm as áreas rurais ocupadas por cerca de $15 \%$ do todo, tendo a população urbana aumentado para aproximadamente $84 \%$ de toda a população brasileira (IBGE, 2010).

Em linhas gerais, é possível afirmar que o êxodo rural decorre fundamentalmente de razões socioeconômicas. No caso brasileiro, é de sabedoria geral o elenco de dificuldades a que, por exemplo, as populações das regiões Norte e Nordeste são submetidas. Ali a realidade impõe o predomínio de latifúndios formados com vistas à acumulação de riquezas por parte de castas privilegiadas, levando a grande maioria das populações a condições sub-humanas de vida (ou sobrevida), onde o acesso à terra é dificultado, as condições de trabalho e educação (quando existem) são indignas, restando a penúria como companhia constante. Tudo isso, somado a alguns fenômenos naturais como secas e enchentes, contribui para determinar que boa parte das populações locais compreenda que abandonar a terra natal e buscar outros centros com maior desenvolvimento de atividades econômicas diversas representará o meio mais lógico para o fim de uma vida de privações e miséria, vindo a migração representar um caminho natural para o alcance de uma vida melhor (IBGE, 2010).

Dowbor, tratando da transformação demográfica do país, afirma:

No campo, permanecem os fatores de empobrecimento da população. $O$ Brasil, segundo o IBGE, tem cerca de 370 milhões de hectares de terra "ótima, boa ou regular" para a agricultura. O Censo Agropecuário de 2006 apesenta um total de 355 milhões de hectares de estabelecimentos agrícolas, sendo que 77 milhões apenas são utilizados para a lavoura... Temos, junto com o continente africano, a maior extensão de terra parada ou subutilizada do planeta. E uma massa de pessoas clamando por terra para cultivar (2016, p. 37-38).

E prossegue:

(...) O êxodo rural explode nos centros urbanos e se manifesta em particular nas novas periferias (...) sem que as administrações locais tivessem possibilidade de garantir saneamento, escola e outras infraestruturas (...). Essa urbanização violenta e caótica (...) coloca a administração municipal na 
linha de frente da nova geração de problemas econômicos e sociais. A pressão explode nos municípios, enquanto escalões superiores continuam com a sua dramática inoperância (...). (2016, p. 39-41).

Tais reflexões reafirmam a problemática em análise, entendo o problema e os colapsos gerados a partir dele.

\subsection{Os aglomerados subnormais}

Segundo o Instituto Brasileiro de Geografia e Estatística (IBGE), no trabalho "Aglomerados Subnormais 2019: Classificação Preliminar e Informações de Saúde para o Enfrentamento à COVID-19", um aglomerado subnormal é

(...) uma forma de ocupação irregular de terrenos de propriedade alheia (pública ou privada) para fins de habitação em áreas urbanas e, em geral, caracterizados por um padrão urbanístico irregular, carência de serviços públicos essenciais e localização em áreas que apresentam restrições à ocupação. No Brasil podem ser conhecidos por diversas denominações: favela, invasão, grota, baixada, comunidade, mocambo, palafita, loteamento, ressaca, vila etc. As denominações e características variam territorialmente. Nessas localidades habitam populações em condições de vulnerabilidade no tocante às condições socioeconômicas, saneamento e habitação. (IBGE, 2020, p. 3).

O estudo apontou que os municípios de São Paulo e do Rio de Janeiro apresentam os maiores números absolutos de domicílios nesta condição, cabendo a São Paulo 529.921 domicílios e ao Rio de Janeiro 453.571 (IBGE, 2020, p. 14). Quando a avaliação se refere às unidades federativas, também São Paulo e Rio de Janeiro se encontram na dianteira, contendo, respectivamente, 1.066 .813 e 717.326 domicílios enquadráveis como aglomerados subnormais. Destaque-se que se encontram nestes estados os aglomerados com maior número de unidades, sendo eles a Rocinha e Rio das Pedras (RJ, 10 e 30 colocados com 25.472 e 22.509 domicílios, respectivamente) e Paraisópolis (SP, 40 colocado com 19.262 unidades).

Evocando a definição de êxodo rural supra exposta, resta nítida a influência dos movimentos migratórios para a consecução desses números, haja vista que se refere exatamente às capitais dos centros de maior PIB bruto e, portanto, de maior 
desenvolvimento econômico do país, funcionando como óbvios polos de atração para aqueles que buscam a chamada "vida melhor".

\subsection{0 "déficit" habitacional}

Segundo o dicionário do Programa Nacional de Capacitação das Cidades CAPACIDADES, do Ministério do Desenvolvimento Regional,

"(...) déficit habitacional" significa "a medida das insuficiências de moradia de uma determinada sociedade. Essas insuficiências não se referem exclusivamente à quantidade de moradias que faltam para abrigar as pessoas, mas também às condições das moradias existentes (BRASIL, 2020).

No tocante ao número de moradias, levantamento realizado em 2019 pela Associação Brasileira de Incorporadoras Imobiliárias (ABRAINC), em parceria com a Fundação Getúlio Vargas (FGV), apontou que o déficit habitacional no país aumentara em 7\% entre os anos de 2007 e 2017, representando 7,78 milhões de unidades habitacionais (ABRAINC, 2019).

O trabalho "Demanda Habitacional no Brasil", publicado pela Caixa Econômica Federal, em 2012, e coordenado por Emmanuel Carlos de Araújo Braz, teve por objetivo a quantificação e qualificação da questão habitacional no país. Ali é evocado o antigo Banco Nacional da Habitação (BNH), afirmando-se:

A política habitacional executada pelo $\mathrm{BNH}$ teve por objetivo viabilizar o acesso à moradia aos diferentes estratos sociais, com foco nas famílias de baixa e média renda... A crise econômica iniciada no final dos anos 70 provocou inflação, desemprego, queda dos níveis salariais, o que gerou desequilíbrio no Sistema Financeiro de Habitação...Tal cenário resultou na extinção do BNH... A pressão populacional nos centros urbanos, a crise econômica, o desemprego e o alto custo do solo urbano associados à ausência de política habitacional forçaram as famílias de menor renda a buscar por conta própria alternativas precárias de moradia. Este processo acelerou a favelização, a ocupação irregular da periferia e de áreas de risco, configurando, desta forma, os atuais problemas urbanos brasileiros. (CAIXA ECONÔMICA FEDERAL, 2012, p. 9). 
Importante destacar a ponderação de Liliana Lavoratti em artigo denominado "Direito só no Papel - Falta de Moradia Afeta Milhões de Brasileiros", publicado na revista Desafios do Desenvolvimento, do IPEA (2009), quando afirma:

(...) O direito à moradia está mais do que assegurado no papel ... Entretanto, os avanços ocorridos na legislação de direito à moradia a partir da Constituição de 1988 não se traduziram em avanços concretos nas condições de habitação e acesso a serviços urbanos da população brasileira. (LAVORATTI, 2009, p.1).

Prossegue citando a fala de Maria Piedade Morais, coordenadora de estudos urbanos do instituto, a qual pontifica:

Os resultados estão aquém do esperado, a começar pelo déficit habitacional estimado em cerca de 7,9 milhões de moradias... Nas zonas urbanas brasileiras ainda há 54,6 milhões de brasileiros que convivem com pelo menos um tipo de inadequação habitacional. (LAVORATTI, 2009, p.1).

No já citado trabalho do IPEA sobre o Estatuto das Cidades e a Habitat III, as pesquisadoras Barbara Marguti e Thêmis Aragão, ao discorrerem sobre habitação e assentamentos precários no Brasil, mencionam que

(...) a transformação do país rural em uma população predominantemente urbana suscitou um debate público que questionava a eficiência das primeiras políticas de produção de moradias promovidas pelos Institutos de Aposentadoria e Pensões (IAPs) e pela Fundação Casa Popular (FCP) nas décadas de 1930 e 1940", mas que "...a agenda da reforma urbana foi interrompida pelo golpe militar de 1964 (...) (ARAGÃO; MARGUTI, 2016, p. 327).

Seguem citando várias passagens em que a atuação dos movimentos populares mereceu destaque na luta pela reforma urbana, como a emenda de reforma urbana dirigida à Constituinte de 1988, a criação do Estatuto das Cidades, a realização da Rio-92, onde foi assinado o "Tratado por Cidades Justas, Democráticas e Sustentáveis", mas pontuam a derrocada das políticas sociais nas décadas de 1980 e 1990, mostrando que 
(...) A ausência de políticas públicas de longo prazo e de programas habitacionais de grande alcance levou parte significante da população dos grandes centros urbanos do país a viver em assentamentos precários, praticamente a única alternativa possível de acesso à moradia" (p.329). Ainda que citando alguns avanços nas políticas habitacional e urbana a partir do governo instalado em 2002 (p. 330), concluem afirmando que "...a formação de assentamentos precários é consequência da exclusão da população de menor renda do mercado formal... Assim, é esperado um aumento da formação de assentamentos precários, dado que os índices de acessibilidade tendem a piorar, e que a ampliação do crédito tem um limite baseado no Sistema Financeiro de Habitação (SFH), o qual não coincide com a dimensão das necessidades habitacionais do país" (ARAGÃO; MARGUTI, 2016, p. 337).

\section{PROGRAMA "MINHA CASA, MINHA VIDA": SOLUÇÃO?}

Instituído pela Lei 11.977/2009 (alterada pela Lei 12.424/2011) e apresentado pelo Ministério do Desenvolvimento como a "maior iniciativa de acesso à casa própria já criada no Brasil", O programa Minha Casa, Minha Vida é exemplo de política pública distributiva de acordo com a tipologia de Theodore J. Lowi, citado por Fernando de Souza Coelho, Valdemir Pires e Leonardo Secchi, quando "(...) os benefícios são concentrados para alguns grupos de atores e os custos são difusos para toda a coletividade/contribuintes (...)" (2020, p. 31). O programa tinha como grande proposta propiciar maior acesso à moradia por famílias de baixa renda, o que também traria como efeitos imediatos o aquecimento da economia e o fortalecimento da indústria da construção civil. Diz a Lei:

Art.10- O Programa Minha Casa, Minha Vida - PMCMV tem por finalidade criar mecanismos de incentivo à produção e aquisição de novas unidades habitacionais ou requalificação de imóveis urbanos e produção ou reforma de habitações rurais, para famílias de até $R \$ 4.650,00$ (quatro mil, seiscentos e cinquenta reais) (...).

Segundo dados fornecidos pela Confederação Nacional dos Municípios (CNM), entre 2009 e 2019 o programa contratara cerca de 5,5 milhões de moradias e entregara aproximadamente 4 milhões, consumindo recursos que giravam em torno de 463,7 bilhões de reais oriundos do orçamento da União e do Fundo de Garantia do Tempo de Serviço- FGTS. O estudo aponta, todavia, que o programa atravessa 
grave crise, com queda de recursos e obras paralisadas, apresentando dificuldades de operacionalização em mais de 80\% dos municípios brasileiros (CNM, 2019).

A pesquisadora Ermínia Maricato, referência nacional em questões de urbanismo e coordenadora da proposta de criação do Ministério das Cidades, aponta problemas graves na execução do programa, notadamente no tocante à falta de gerenciamento efetivo pelo poder público e à falta de sensibilidade quanto às reais necessidades do público destinatário.

Em entrevista concedida ao site BBC News - Brasil em junho de 2018, a professora afirma que

Tivemos um movimento intenso de obras, mas quem o comandou e definiu onde se localizariam não foi o Governo Federal, mas sim interesses de proprietários imobiliários, incorporadores e empreiteiras". Prossegue destacando que "Conjuntos residenciais do programa erguidos longe dos centros urbanos levarão várias décadas para se integrar às cidades. Esse investimento gigantesco, somado a uma especulação de terras ciclópica, tornou as cidades ainda mais inviáveis no Brasil", e cita os exemplos de Câmaras Municipais que, visando atrair obras, passaram a estender os limites dos municípios, chegando a incluir fazendas nos perímetros urbanos: "O que acontece nos fins de semana nos conjuntos habitacionais criados nessas áreas? O ônibus não vai, você tem um exílio na periferia... Os novos bairros também são mais difíceis de policiar e vulneráveis ao crime organizado... A cidade segura é compacta, com mix de uso: tem moradia e trabalho, está viva de dia e de noite" (FALLET, 2018).

Ao tratar da necessidade de democratização nos processos de tomada de decisão, com maior participação da população local diretamente interessada nas políticas públicas, Dowbor também exemplifica incorreções no desenvolvimento do Programa Minha Casa, Minha Vida, afirmando que

(...) é necessário um intenso esforço para a abertura de espaços, entretanto, não basta descentralizar recursos para as prefeituras, há uma grande necessidade de controle dos cidadãos sobre a gestão municipal desses recursos. (DOWBOR, 2016, p. 45)

Se pensarmos que o tão citado déficit habitacional se refere a aspectos quantitativos, mas também qualitativos (alusivos à funcionalidade efetiva das unidades habitacionais disponibilizadas), vale evocar o ensinamento de Chrispino, ao 
discorrer sobre os elementos constitutivos das políticas públicas transparentes, com destaque para a finalidade. Aponta o mestre que "devemos sempre vincular a política transparente ao interesse público a ser buscado pelo governante. É indispensável que a decisão de fazer explicite a finalidade que busca" (2016, p. 117). Chega-se à conclusão de que, ao menos no aspecto qualitativo do problema habitacional, as políticas implementadas no âmbito do Programa Minha Casa, Minha Vida deixaram de atender a este importante elemento, certamente em razão do que foi identificado pela professora Ermínia Maricato (citada acima), uma vez que as políticas deixaram de considerar aquilo que verdadeiramente representava as carências do público-alvo.

\section{CONSIDERAÇÕES FINAIS}

É possível afirmar que as ideias de Lefebvre não foram abandonadas e que pode vir a ser concretizado o sonho de uma cidade para todos, urbana ou rural, onde viver e sobreviver não sejam expressões sinônimas. Onde a vida represente estar em contato com todos os ingredientes que permitam a fruição de plena cidadania: saúde, educação, trabalho digno, lazer, moradia. Em outras palavras, onde a regra não seja a privação, mas a liberdade.

No aspecto legal, as ferramentas de efetivação do direito à cidade vão sendo paulatinamente estabelecidas, significando notável avanço, mas as necessidades das populações vão muito além da "boa vontade legislativa". Não se vive em livros, vive-se o dia a dia das ruas, das nossas potencialidades e limitações, exigindo-se que a realidade ideal das normas escritas seja definitivamente transposta para o mundo dos fatos.

Quando se olha o mapa das cidades, percebe-se a presença de senzalas urbanas. O desafio é pensar além da distribuição de renda e do desenvolvimentismo. É necessário pensar na distribuição de cidade, pois uma casinha é muito fácil de se construir (SANTOS, 2017). Não basta que a moradia seja atualmente reconhecida como direito fundamental, essencial à existência humana e iminentemente ligado à dignidade de vida. É preciso avançar, dar praticidade e 
eficácia aos discursos, pois a justiça social precisa significar a oferta de vida digna, segura, feliz.

A plenitude do direito à moradia, do acesso à habitação humanizada precisa levar em conta a perspectiva do cidadão, seus anseios e sua visão de mundo melhor. Não se faz política pública desprezando a experiência daqueles que sofrem com os problemas que se pretende resolver. Deve-se aprender com a experiência de Grenoble, citada por Dowbor, mas também com a realidade estampada nos jornais de todo o país, em que imóveis são invadidos por criminosos ou simplesmente não são assumidos por aqueles que deveriam ocupá-los, tudo devido a planejamentos inadequados, muitas vezes ligados a interesses corporativos e divorciados dos verdadeiros anseios da única razão de ser de uma política pública: o cidadão.

O simples fato de ser criada uma unidade habitacional pode representar a redução do déficit pelo aspecto numérico. Mas quando tal imóvel está situado em área remota, afastada dos centros de atividade econômica e social, esta política não estará vinculada a qualquer avanço verdadeiro. Ao contrário, se o tempo de deslocamento entre a casa e o trabalho, por exemplo, vier a proporcionar desconforto e sacrifício, se as cercanias da nova moradia são desprovidas de uma mínima estrutura de serviços (transporte, lazer, educação, saúde), isso representará qualquer coisa, menos uma conquista social.

Chrispino cita com propriedade o escritor inglês Gilbert Keith Chesterton (1874-1936), que pontificou: "Não é que os políticos não vejam a solução. O que eles não enxergam é o problema" (2016, p. 21). Sem buscar a correta compreensão do problema social sob todas as suas vertentes e, principalmente, sem levar em conta a relevância da dimensão humana, do foco no bem-estar do cidadão, estaremos sempre distantes dos motivos legítimos para formulação de políticas públicas.

Vale recordar a tão aplaudida Lei Áurea como um exemplo claro de descompasso entre o problema a ser enfrentado e a finalidade a ser conseguida. Vislumbrou-se a prática escravocrata como "o problema" a ser sanado com a garantia de liberdade disseminada ao povo até então cativo. O que se viu, na 
prática, foi que os "efeitos perversos" daquele ato administrativo representaram a outorga, à população negra, da "liberdade" para o exercício de nenhuma cidadania: sem casa, sem trabalho, sem fontes de subsistência, com todas as portas abertas para o nada.

\section{REFERÊNCIAS}

AMANAJÁS, R; KLUG, Letícia. Direito à Cidade, Cidades para Todos e Estrutura Sociocultural Urbana. In: COSTA, M. A. et al. (org.). A Nova Agenda Urbana e o Brasil: insumos para sua construção e desafios a sua implementação. Brasília: IPEA, 2018. Disponível em:

http://repositorio.ipea.gov.br/bitstream/11058/8622/1/Direito\%20\%C3\%A0\%20cida de.pdf. Acesso em: 22 out. 2020.

ARAGÃO, T. A.; MARGUTI, B. O. Habitação e assentamentos precários no Brasil: trajetória e desafios para o alcance da justiça espacial. In: COSTA, Marco Aurélio(org.). O Estatuto da Cidade e a Habitat III: Um Balanço de Quinze Anos da Política Urbana no Brasil - A Nova Agenda Urbana. Brasília: IPEA, 2016. cap. 13

ASSOCIAÇÃO BRASILEIRA DE INCORPORADORAS IMOBILIÁRIAS. Déficit Habitacional é Record no Brasil. São Paulo: ABRAINC, 2019. Disponível em: https://www.abrainc.org.br/noticias/2019/01/07/deficit-habitacional-e-recorde-n o-pais. Acesso em: 22 out. 2020.

BRASIL. [Constituição (1988)]. Constituição da República Federativa do Brasil de 1988. Brasília, DF: Presidência da República. Disponível em: http://www.planalto.gov.br/ccivil_03/constituicao/constituicao.htm. Acesso em: 22 out. 2020.

BRASIL. Ministério do Desenvolvimento Regional. Déficit habitacional. Brasília: MDR, 2020. Disponível em: http://www.capacidades.gov.br/dicionario/index/letra/d. Acesso em: 22 out. 2020.

BRASIL. Lei no 11.977, de 7 de julho de 2009. Dispõe sobre o Programa Minha Casa, Minha Vida - PMCMV e a regularização fundiária de assentamentos localizados em áreas urbanas; altera o Decreto-Lei no 3.365, de 21 de junho de 1941, as Leis nos 4.380, de 21 de agosto de 1964, 6.015, de 31 de dezembro de 1973, 8.036, de 11 de maio de 1990, e 10.257, de 10 de julho de 2001, e a Medida Provisória no 2.197-43, de 24 de agosto de 2001; e dá outras providências. Brasília, DF: Congresso Nacional, [2009]. Disponível em: http://www.planalto.gov.br/ccivil_03/_ato2007-2010/2009/lei/l11977.htm. Acesso em: 22 out. 2020. 
CAIXA ECONÔMICA FEDERAL (Brasil). Demanda Habitacional no Brasil. Brasília: Caixa, 2012. Disponível

em: https://www.caixa.gov.br/Downloads/habitacao-documentos-gerais/demanda_ha bitacional.pdf. Acesso em: 22 out. 2020.

CALDAS, R.W. (Coord.) Políticas Públicas - Conceitos e Práticas. Belo Horizonte: SEBRAE/MG, 2008.

CARTA mundial pelo direito à cidade. Fórum Mundial Policêntrico, 2005.

Disponível em: www.direitoambiental.com.br. Acesso em: 22 out. 2020.

CHRISPINO, A. Introdução ao Estudo das Políticas Públicas: Uma Visão Interdisciplinar e Contextualizada. Rio de Janeiro: Editora FGV, 2016.

COELHO, F.S.; PIRES, V.; SECCHI, L. Políticas Públicas: Conceitos, Casos Práticos, Questões de Concursos. 3. ed. São Paulo: CENGAGE, 2020.

CONFEDERAÇÃO NACIONAL DOS MUNICÍPIOS. CNM faz análise dos 10 anos do Minha Casa, Minha Vida. Agência CNM de Notícias, Brasília, 25 mar. 2019. Disponível em:

https:/www.cnm.org.br/comunicacao/noticias/cnm-faz-analise-dos-10-anos-do-minha -casa-minha-vida. Acesso em: 22 out. 2020.

DOWBOR, Ladislau. O Que é o Poder Local? Maranhão: Editora Ética, 2016.

ÊXODO rural. In: Significados. Matosinhos: 7graus, 2020. Disponível em: https://www.significados.com.br/exodo-rural/. Acesso em: 22 out. 2020.

FALLET, J. Minha Casa, Minha Vida piorou a vida nas cidades e alimentou a especulação imobiliária. BBC Brasil, São Paulo, 4 jun. 2018. Disponível em: https://www.bbc.com/portuguese/brasil-44205520. Acesso em: 22 out. 2020.

HARVEY, D. Cidades Rebeldes: Do Direito à Cidade à Revolução Urbana. Trad. Jefferson Camargo. São Paulo: Editora Martins, 2014.

INSTITUTO BRASILEIRO DE GEOGRAFIA E ESTATÍSTICA. Aglomerados

Subnormais 2019: Classificação Preliminar e Informações de Saúde para o Enfrentamento à COVID 19. Rio de Janeiro: IBGE, 2020. Disponível em: www.agenciadenoticias.ibge.gov.br. Acesso em: 22 out. 2020.

INSTITUTO BRASILEIRO DE GEOGRAFIA E ESTATÍSTICA. Censo Demográfico de 2010. Rio de Janeiro: IBGE, 2010. Disponível em: www.censo2010.ibge.gov.br. Acesso em: 22 out. 2020.

LAVORATTI, L. Direito só no Papel: Falta de Moradia Afeta Milhões de Brasileiros. IPEA Desafios do Desenvolvimento. Brasília, ano 6, n. 51, 07 jun. 2009. 
MARGUTI, B. O.; COSTA, M. A.; GALINDO, E. P. A trajetória brasileira em busca do direito à cidade: os quinze anos de estatuto da cidade e as novas perspectivas à luz da nova agenda urbana. In: COSTA, Marco Aurélio(org.). O Estatuto da Cidade e a Habitat III: Um Balanço de Quinze Anos da Política Urbana no Brasil - A Nova Agenda Urbana. Brasília: IPEA, 2016. p. 11-25. Disponível em:

https://www.ipea.gov.br/portal/index.php?option=com_content\&view=article\&id=28 583. Acesso em: Acesso em: 22 out. 2020.

ORGANIZAÇÃO DAS NAÇÕES UNIDAS. Declaração Universal dos Direitos

Humanos. Paris: ONU, 1948. Disponível em: www.unicef.org. Acesso em: 22 out. 2020.

SANTOS, J. V. A Distribuição de Cidade Contra a Senzalização da Metrópole. IHU on-line, São Leopoldo, 7 fev. 2017. Disponível em:

https://ihu.unisinos.br/159-noticias/entrevistas/564621. Acesso em: 22 out. 2020.

SECCHI, L. Análise de Políticas Públicas: Diagnóstico de Problemas, Recomendação de Soluções. São Paulo: CENGAGE, 2021. 